\title{
Research on Impact of Aging Population on the Economy in Sichuan and Its Countermeasures
}

\author{
Yuyan Zhou \\ Jincheng College \\ Sichuan University \\ Chengdu, China
}

\author{
Yanjun Shi \\ Jincheng College \\ Sichuan University \\ Chengdu, China
}

\begin{abstract}
In face of the background of aging population around the world, this article, rooted in Sichuan province, analyzes main characteristics of the province including large population base, rapid growth, growing older before making rich, imbalance between urban and rural development as well as few children, discusses the impact of aging population on the economic development with countermeasures proposed, and the author makes innovative suggestions that an individual separate account be set up for the pension insurance fund, according to the insured's ability to take risks, the premium will be used for investment at a high, medium and low risk, which will be managed by the authorized fund companies, and it can be used as references for the actual operation to some degree.
\end{abstract}

Keywords—aging population; pension security; economy

\section{INTRODUCTION}

Young people have been predominating in the age structure of human society for a long time, yet the improved sanitary conditions and living levels have promoted a widespread increase to the human lifespan, and the "silver hair" tides have taken placed throughout the world. The aging population is an impersonal phenomenon that cannot be reversed and it has become a significant issue for the whole human society to concern about.

Sichuan is a large province in China, where the aging develops severely, plus the poor economy, large base, rapid growth as well as urban-rural inversion. Therefore, it will make a significant sense for this article to discuss the impact of the aging on the economy and seen countermeasures on the basis of analyzing the characteristics of the aging population in the province.

\section{Main Characteristics OF Aging POPUlation IN SICHUAN}

\section{A. Large Base and Rapid Growth}

According to the sampling survey data of $1 \%$ population in Sichuan province by the end of Nov 1, 2015 at zero o'clock, the residents aged 60 or above totaled 16.72 million, occupying $20.38 \%$ of the total, of whom, those aged 65 or above totaled 10.94 million, occupying $13.33 \%$.

According to the 6th national census data in 2010, the residents aged 60 or above totaled 13.11 million, occupying
$16.3 \%, 3.04 \%$ higher than the average value of the country, of whom, those aged 65 or above totaled 8.8075 million, occupying $10.95 \%, 2.08 \%$ higher than the average level of the country. According Table 1, compared to that in 2015, the short five years witnessed a rapid growth of the aging population in Sichuan. Within the five years, those aged 60 or above were in an increase of $27.54 \%$ up to 3.61 million; and those aged 65 or above $24.22 \%$ up to 2.133 million.

TABLE I. AGING PopUlation StATISTICS OF THE 6TH NATIONAL CENSUS IN SICHUAN

\begin{tabular}{|c|c|c|c|c|}
\hline Population & $\begin{array}{c}\text { Population } \\
\text { (unit: ten } \\
\text { thousand) }\end{array}$ & $\begin{array}{c}\text { Proportion } \\
\text { in the } \\
\text { province } \\
(\%)\end{array}$ & $\begin{array}{c}\text { Average } \\
\text { Proportion } \\
\text { in the } \\
\text { Country } \\
(\%)\end{array}$ & $\begin{array}{l}\text { Higher than } \\
\text { National } \\
\text { Average } \\
\text { Proportion } \\
(\%)\end{array}$ \\
\hline 60 or above & 1311 & 16.30 & 13.26 & 3.04 \\
\hline 65 or above & 880.75 & 10.95 & 8.87 & 2.08 \\
\hline
\end{tabular}

\section{B. Growing Older before Making Rich}

According to the UN standards, a country or region will be considered to have entered the aging society if the elderly aged 60 or above occupy $10 \%$ of the total population or the elderly aged 65 or above occupy $7 \%$ of the total. In 1990, the elderly aged 60 or above exceeded $10 \%$ of the total in China, where the aging society came earlier, and worse, Sichuan entered the aging society in 1997. It is know that it took about one hundred years for developed countries to enter the aging society after being rich, yet it took only several decades for China to enter earlier the aging society when it was still in poverty. When entering the aging society in 1997 , its per capita GNP totaled 600 dollars only, but the developed countries had their GNP reach 5000-10000 dollars when entering the aging society, which was 8-16 times Sichuan province.

\section{Aging Population Accompanied by Few Children}

The status quo of few children is another issue going together with the aging population. According to the demography, a society will be considered to have entered a few children period if the children aged 0-14 occupy 18-20\% of the total population, it will be considered severe if the proportion is $15 \%-18 \%$ and extremely severe if the proportion is below $15 \%$. In 2015, the children aged 0-14 occupied $17.6 \%$ 
in China, which was in a severe situation, yet it was worse in Sichuan, according to the 6th national census in Sichuan, the population aged $0-14$ totaled $13,644,450$, occupying $16.97 \%$ of the total, and this province had been in a severe situation of few children prior to other provinces in the country in 2010.

\section{Imbalance in Aging Development, Urban-Rural Inversion}

According to the 6th national census in Sichuan (Table 2), the aging development was imbalanced in different regions in Sichuan, especially the aging in Ziyan and Meishan was severe, both reaching $13 \%$, yet the aging in the capital city Chengdu was not severe and the elderly occupied $9.71 \%$ only. Minority areas such as Aba, Ganzi and so on keep young age structure due to the little influence by the family planning policy. Main causes for the imbalanced aging between urban and rural areas are the acceleration of urbanization, movement of rural young laborers to urban areas, and those staying in villages are mostly the elderly and children. According to the data comparison between the 5th and the 6th national census in Sichuan, the population increased 10,081,682 in urban areas, and decreased $12,954,417$ in rural areas, and the population proportion increased by $13.49 \%$ in urban areas. Yet, according to the data comparison between the sampling survey in 2015 and the 6th national census in Sichuan, the population increased another 6.81 million in urban areas and decreased 5.19 million in rural areas, and the population proportion increased by $7.51 \%$ in urban areas. And $70 \%$ of those moving from rural areas to urban areas were young people, which finally caused a more severe aging population in rural areas.

TABLE II. Statistics of Aging Population In Regions, Sichuan, SHOWN IN THE 6TH CENSUS

\begin{tabular}{|l|l|l|l|l|}
\hline No. & \multicolumn{1}{|c|}{ Region } & $\begin{array}{c}\text { Total } \\
\text { Population }\end{array}$ & $\begin{array}{c}\text { Aging } \\
\text { Population }\end{array}$ & $\begin{array}{c}\text { Proportion of } \\
\text { Aging } \\
\text { Population } \\
\text { (\%) }\end{array}$ \\
\hline 1 & Ziyang & 3665064 & 496873 & 13.60 \\
2 & Meishan & 2950548 & 392922 & 13.32 \\
3 & Zigong & 2678898 & 339291 & 12.67 \\
4 & Guang'an & 3205476 & 402688 & 12.56 \\
5 & Leshan & 3235756 & 396131 & 12.24 \\
6 & Nanchong & 6278622 & 753272 & 12.00 \\
7 & Neijiang & 3702847 & 438639 & 11.84 \\
8 & Deyang & 3615759 & 421471 & 11.66 \\
9 & Mianyang & 4613873 & 537687 & 11.65 \\
10 & Suining & 3252551 & 370485 & 11.39 \\
11 & Guangyuan & 2484123 & 276883 & 11.15 \\
12 & Dazhou & 5468092 & 596506 & 10.91 \\
13 & Ya'an & 1507264 & 163981 & 10.88 \\
14 & Yibin & 4472001 & 472078 & 10.56 \\
15 & Bazhong & 3283771 & 343877 & 10.47 \\
16 & Chengdu & 14047625 & 1364348 & 9.71 \\
17 & Panzhihua & 1214121 & 110850 & 9.13 \\
18 & Aba & 898713 & 65430 & 7.28 \\
19 & Liangshan & 4532809 & 321815 & 7.10 \\
20 & Ganzi & 1091872 & 71002 & 6.50 \\
21 & Luzhou & 4218426 & 231668 & 5.49 \\
\hline & \multicolumn{2}{|l}{ bate source: Bulletin of the 6th national census data in 2010, Sichuan } \\
& & \multicolumn{3}{|l}{}
\end{tabular}

\section{THE IMPACT OF AGING POPULATION ON SICHUAN'S ECONOMY}

\section{A. Cost Increased for the Economic Development}

The aging population causes the increase of costs for the economic development, seen for authorities, the increase of the elderly represents a decrease of productive population, on the one hand, it weakens the absolute productivity of the province; on the other hand, it will cause more expenditure of authorities in pension, medical care and healthcare. Seen from employers, on the one hand, the decrease of laborers will cause the risen pay to employees, an increase in production cost. On the other hand, the increase of retirees adds more pressure for the employers for social premium payment. According to the 2014 Sichuan Statistics Yearbook, the proportion between employees in urban areas and retirees and the resigned was reduced from 16.6 in 1978 to 5.4 in 2000 and 2.1 in 2014. It meant that in 1978 , there were about 16.6 workers to serve a retiree, yet in 2014 , there were only 2.1 workers to serve a retiree, obviously we can see how heavy the pension pressure was in Sichuan.

Seen form Table 3, with a short 15 years from 2000 to 2014, the retirees in Sichuan increased from 2.024 million in 2000 to 7.173 million in 2014 , up 2.5 times. The insurance welfare for the elderly increased from 13892.71 million yuan in 2000 to 126550.60 million yuan 2014 , up 8 times.

TABLE III. STATISTICS OF INSURANCE WELFARE OF THE RETIREES

\begin{tabular}{|c|c|c|c|}
\hline Year & $\begin{array}{l}\text { Retiree and the } \\
\text { Resigned } \\
\text { (Unit: ten } \\
\text { thousand } \\
\text { persons) }\end{array}$ & $\begin{array}{l}\text { Proportion between } \\
\text { Retiree and the } \\
\text { Resigned and All } \\
\text { Urban Employees } \\
\text { (taking the number of } \\
\text { retiree and the } \\
\text { resigned as 1) }\end{array}$ & $\begin{array}{c}\text { Insurance } \\
\text { Welfare Sum } \\
\text { (Ten thousand } \\
\text { yuan) }\end{array}$ \\
\hline 2000 & 202.40 & 5.4 & 1389271 \\
\hline 2001 & 214.37 & 5.2 & 1519083 \\
\hline 2002 & 227.92 & 4.9 & 1824883 \\
\hline 2003 & 237.70 & 4.9 & 1935548 \\
\hline 2004 & 249.80 & 4.8 & 2179324 \\
\hline 2005 & 274.86 & 4.5 & 2440594 \\
\hline 2006 & 290.10 & 4.4 & 2927512 \\
\hline 2007 & 317.40 & 4.1 & 3740000 \\
\hline 2008 & 382.40 & 3.4 & 4681044 \\
\hline 2009 & 441.03 & 3.1 & 6236666 \\
\hline 2010 & 485.50 & 2.8 & 7499570 \\
\hline 2011 & 559.00 & 2.5 & 7624606 \\
\hline 2012 & 609.20 & 2.4 & 8874404 \\
\hline 2013 & 663.54 & 2.3 & 10718868 \\
\hline 2014 & 717.30 & 2.1 & 12655060 \\
\hline
\end{tabular}

\section{B. The Aging Population with Few Children Enlarges the} Gap between the Pension Insurance Fund Income and Expenditure

The rapidly aging population in Sichuan has increasingly enlarged the gap between the pension insurance fund income and expenditure. First of all, more retirees and more people require more payment of the pension insurance funds. The number of retirees in Sichuan increased from 280,800 in 1978 to 7.173 million in $2014,25.5$ times that in 1978 . Second, it is 
low birth rate, increasingly severe trend of few children as well as the decreased number of people to pay the insurance pension fund. The birth rate in Sichuan reduced from $41.0 \%$ in 1952 to $10.22 \%$ in 2014 , going with the lowed birth rate, the income of pension insurance fund is reduced, which worsens the imbalance between the pension insurance fund income and expenditure; Finally lowed death rate and prolonged average lifespan increase the period for the pension insurance fund payment. The death rate in Sichuan lowed from $18.2 \%$ in 1952 to $7.02 \%$ in 2014 , which was greatly reduced, the longer the insured live, the longer the pension insurance fund payment is made, which caused an increased gap between the pension insurance fund income and expenditure.

\section{The Aging Population Is A Barrier for the Rapid Economy Development}

The aggregate supply of a society depends on labor, capital stock and technical level, namely $\mathrm{y}=\mathrm{f}(\mathrm{N}, \mathrm{K})$. N means labor, $\mathrm{K}$ means capital stock, $\mathrm{y}$ means total yield. The total yield keeps a positive correlation with the labor input, capital stock and technical level. As a province large in population, Sichuan has its rapid economic development depend on the laborer supply adequate and in a low cost. However, going with the aging population progress, its advantage in the population for the economic development is disappearing. A great number of retirees will be out of the laborers, besides, there are no adequate young laborers to make up. According to the national $1 \%$ population survey data in 2015 , Sichuan, the population aged 15-59 totaled 52.03 million, occupying $63.42 \%$ of the total in the province. The absolute reduction in the number of laborers and the aging population make the laborers severely inadequate, and the increased labor costs have been a block for the economic development in Sichuan. In the meantime, due to the inadequacy of laborers, the industries in China have gradually been transformed from labor intensive type to the technical intensive type, and higher requirements are raised for the laborers. However, among the population aged 15-59, those who receive college education or above occupy $9.00 \%$, those who receive senior high school or above occupy $12.82 \%$. And the inadequacy of high quality laborers will put severe influence to the economic development in the province.

\section{The Aging Population Is A Barrier for the Urban and Rural Development in Harmony}

Though the aging population has a large base in Sichuan, yet it is in an imbalanced development, showing an urban-rural inversion. A great number of rural laborers leave rural areas, according to the statistics yearbook of Sichuan, in 2000 the rural laborers leaving the province totaled about 6 million, which was up to 10.5 million in 2010. Most of the rural laborers leaving rural areas were young people, of whom, $64.17 \%$ were young people aged $15-44$. However, most of the rural laborers were unable to obtain identities of local citizens, who have to return home after retirement. The young laborers leaving the rural areas and those who return home after retirements further worsen the aging population in rural areas, Sichuan province, which solidify the urban-rural dual structure, severely blocking the urban-rural development in harmony.

\section{CONCLUSION AND COUNTERMEASURES}

Seen from the research mentioned above, we have a clear finding that the aging population in Sichuan is extremely severe. It has not only a large base in population, growing quickly but also enters the aging society early with is per capita GNP equal to less one tenth of that in developed countries, which produces more pressure to the province that is still not rich. Meanwhile, the aging population is accompanied with the few children phenomenon due to the family planning policy, as a result, the gap between the pension insurance fund income and expenditure is further enlarged in the province. plus, the leaving of rural young people and the increased labor costs have seriously blocked the rapid economic development in Sichuan. Therefore, this article raises several suggestions for the problems mentioned above:

\section{A. Postpone the Time to Retire and Encourage the Birth}

The retirement age and system that we carry out currently are based on the background where the average lifespan was less than 50 years in the 1950s. But nowadays, the average lifespan of the people in Sichuan is nearly 80 years, obviously the rule which requires men to retire at 60 and women at 55 is unsuitable for the time. In addition, most of the retirees are unwilling to leave the posts of their own, hoping to make more contributions to the society. So we suggest to modify the retirement system to properly postpone the age to retire. Considering that the posts that the elderly continue taking will bring pressure to the employment and promotion of new employees, we may arrange the elderly aged 60 or above to other easy posts or those suitable for them to work, leaving important posts to young people.

Besides, in order to raise the total birth rate and increase the dependent's proportion of laborers, based on the secondchild policy in the country, the Sichuan authorities are expected to issue corresponding birth and education policies to encourage the birth. For example, the compulsory education can spread to kindergarten, preferential policies will be given to the families which have two children to buy a house with larger area, or subsides will be given to the families which have two children and so on.

\section{B. Set up Pension Insurance Fund Individual Separate Account and Increase Channels for Investment}

The severe aging population in the province makes it much heavier for the payment of pension insurance fund, plus the lowed birth rate also brings a decrease of the premium income for the pension insurance fund. If the return on investment (ROI) of the premium is unable to increase, which is invested to the low-benefit safety channels, the payment of pension will be difficult to continue in the future, and the great increase of fiscal subsidies even causes financial crisis. So it needs to expand the investment channels for the pension insurance funds. For the pension shall be made in a secure payment, it is inapplicable to invest all of it to high-risk channels. It is suggested that the social pooling of the pension insurance fund be invested in secure channels, and the pension insurance funds will be divided into three levels (high, medium and low) according to the investment benefits and risks. The employees may select according to what they can bear, high returns will 
be given for high risk accounts, and low returns for low-risk accounts. Employees will sign contracts with funds companies which will manage the capital in individual accounts as agents, and the employees have to take the risks at the costs of their own. The fee payment in the social pooling is completed separated from the fee payment in individual accounts, and the funds in the social pooling accounts will also managed by funds companies with no risk level set, which will be invested to low risk and secure projects.

\section{Adjust Industrial Layouts, Attract the Return of Laborers and Strive to Develop the Silver-Hair Industry}

Main causes for the output of a great number of rural young laborers in Sichuan are the low level development of industry and tertiary industry in the province, which make it uneasy to attract local rural laborers. So it needs to well adjust the industrial layout, make full efforts to develop the local industry and tertiary industry, offering more posts to attract the return of laborers so as to relieve the aging population crisis in the province. Meanwhile, it needs to intensify the urban-rural interaction, accelerate the urbanization development to achieve the urban-rural overall development.

Due to the differences in consumption needs by the elderly, with the development of the aging population, the social consumption structure will change as well. So we should follow the market demands and adjust the production supply, for example, we can expand the production of products such as medical products and so on. In addition, the retirees have more time for tourism, so the authorities should catch the chance to develop tourism relying on the unique natural landscapes in Sichuan and around, and build it into a new economic growth point in the province.

\section{REFERENCES}

[1] Wang Lijuan, Discussion on the Impact of Aging Population on the Economy-Based on Sichuan [J] Industrial Economics, 2016(21):60-61

[2] Huang Chunyuan, Quantitative Analysis of the Impact of Aging Population on Financial Steadiness in China[J] Northwest Population Journal, 2015(2):13

[3] Sichuan Bureau of Statistics, Bulletin of National 1\% Population Sampling Survey in 2015, Sichuan [Z]

[4] Sichuan Bureau of Statistics, Bulletin of Main Data of the 5th Census in 2000 and the 6th Census in 2010, Sichuan [Z]

[5] Xiao Yanhua, Aging Population of China in the 21st Century and Reform of Pension Insurance Individual Account-Also Discussing the Policy Selection for Basic Pension Pooling in the 12th Five-Year Plan [J], Shanghai Economic Review, 2011(12):88-90

[6] Sichuan Bureau of Statistics, Sichuan Statistics Yearbook during 20002015 [Z]

[7] Peng Xizhe, Hu Zhan, Aging Population in China at the Public Policy Perspective [J] Social Sciences in China, 2011(3):132

[8] Liu Qiongzhi, Lu Yue, Financial Expenditure and Economic Growth under the Background of Aging Population [J]. Assets and Finances in Administration and Institution 2016(10):4-5.

[9] General Report Drafting Group, General Report of Strategic Research by National Response to Aging Population [J] Scientific Research on Aging, 2015(3):4-5 